\title{
Platelet-derived growth factor-C functions as a growth factor in mouse embryonic stem cells and human fibrosarcoma cells
}

Tomoaki Kinjo 1,3 ${ }^{1,}$ Chuanhai Sun 1,4, Tomomi Ikeda², Takako Ikegami ${ }^{2}$, Yuhki Tada 1,5, Tadayuki Akagi', Takashi Yokota ${ }^{1}$ and Hiroshi Koide ${ }^{1,2^{*}}$ (i)

* Correspondence: h-koide@ juntendo.ac.jp

${ }^{1}$ Department of Stem Cell Biology, Graduate School of Medical Sciences, Kanazawa University, Kanazawa, Ishikawa, Japan ${ }^{2}$ Laboratory of Molecular and Biochemical Research, Research Support Center, Juntendo University Graduate School of Medicine, 2-1-1 Hongo, Bunkyo-ku, Tokyo 113-8421, Japan

Full list of author information is available at the end of the article

\begin{abstract}
Background: Platelet-derived growth factor-C (PDGF-C) has been shown to be involved in several biological processes, such as embryonic development, wound healing and angiogenesis, as well as in diseases including tumor formation and fibrotic diseases. However, its role in fibrosarcoma and embryonic stem (ES) cells has not been elucidated.

Methods: The expression level of PDGF-C was measured using RT-PCR. The activity of PDGF-C was suppressed using RNA interference or a neutralizing antibody and the effect on cell growth was examined using the WST and soft agar assays.

Results: In the tumor cell lines studied, the highest level of PDGF-C expression was in human HT1080 fibrosarcoma cells. In ES cells, it was highly expressed in the self-renewal state but not in the differentiated state. PDGF-C knockdown suppressed anchoragedependent and -independent growth of HT1080 and ES cells. In addition, the suppression of PDGF-C activity by a neutralizing antibody retarded ES cell growth.
\end{abstract}

Conclusion: Our results suggest that PDGF-C plays an important role in the proliferation of fibrosarcoma and ES cells.

Keywords: Embryonic stem cells, Cancer, PDGF-C, Fibrosarcoma, Anchorage-independent growth

\section{Background}

Embryonic stem (ES) cells, which are derived from pluripotent cells of the early mammalian embryo, can grow without limit in the undifferentiated state. In mouse ES cells, the addition of leukemia inhibitory factor (LIF) to the culture medium enables them to maintain their self-renewal and pluripotency. Several transcription factors, including Oct3/4 and STAT3, play important roles in the self-renewal of ES cells by forming transcription factor networks to stimulate the expression of a set of genes that promote self-renewal in ES cells [1].

Interestingly, ES cells share many biological properties with cancer cells [2]. Both ES and cancer cells can survive and grow in the absence of anchorage, and thus produce tumors when injected into nude mice. Several oncogenic pathways, including the STAT3 and Wnt/ $\beta$-catenin pathways, play important roles in ES cell self-renewal [3-8]. Moreover, there is an overlap in the expression of certain genes in ES and cancer cells [9].

(c) The Author(s). 2018 Open Access This article is distributed under the terms of the Creative Commons Attribution 4.0 International License (http://creativecommons.org/licenses/by/4.0/), which permits unrestricted use, distribution, and reproduction in any medium, provided you give appropriate credit to the original author(s) and the source, provide a link to the Creative Commons license, and indicate if changes were made. The Creative Commons Public Domain Dedication waiver (http://creativecommons.org/ publicdomain/zero/1.0/) applies to the data made available in this article, unless otherwise stated. 
These similarities indicate that some genes expressed in self-renewing ES cells might possibly play important roles in cancer cell growth. To further evaluate this, we have been searching for genes that are expressed in self-renewing ES cells, but not in differentiated ES cells. We have identified several self-renewal-specific genes, including Zfp57, Gabpo, Eed, Dax1, Sddr/Ooep, Zfp296 and E2f3a [10-16]. Of these, we have demonstrated that Zfp57 can function as a novel oncogene [17].

The results of a preliminary microarray analysis conducted during this search raised the possibility that platelet-derived growth factor-C (PDGF-C) is expressed in self-renewing ES cells. PDGF-C is a member of the PDGF family, which regulates various cellular processes, such as cell proliferation and motility, both under normal physiological conditions and during the pathogenesis of a number of human diseases, including tumorigenesis [18-21].

While PDGF-A and -B are secreted as active hetero- or homo-dimers, PDGF-C and $-\mathrm{D}$ are secreted as latent homodimers consisting of an N-terminal CUB domain and a C-terminal growth factor domain (GFD) [18, 21]. Proteases, such as plasmin and tissue plasminogen activator, proteolytically cleave the latent PDGF-C, and thus release the GFD from the CUB domain. The GFD binds to and stimulates its cognate receptor, PDGF receptor alpha (PDGF-R $\alpha$ ) [19, 22]. The GFD of PDGF-C can also activate PDGF-R $\beta$ through the formation of the PDGF-R $\alpha \beta$ heterodimer.

Several studies have suggested that PDGF-C plays an important role in tumorigenesis. For example, oncogenic chimeric protein EWS/FLI stimulated PDGF-C expression in Ewing family tumors [23]. In addition, the expression of a dominant-negative mutant of PDGF-C suppressed anchorage-independent growth in Ewing sarcoma cells [24]. These observations suggest that PDGF-C regulates cell growth in Ewing sarcoma. However, little is known about the role of PDGF$\mathrm{C}$ in the growth of fibrosarcoma, another type of sarcoma. Therefore, we first examined whether PDGF-C promotes fibrosarcoma cell growth. Considering the similarity between ES and cancer cells, we then examined a possible involvement of this growth factor in ES cell growth. Our results suggest that PDGF-C functions as a growth factor of both fibrosarcoma cells and ES cells.

\section{Methods}

\section{Cell lines and reagents}

The fibrosarcoma cell line HT1080 was obtained from the Health Science Research Resources Bank (HSRRB). Cells were cultured in Dulbecco's modified Eagle's medium (DMEM; Nacalai Tesque) supplemented with 10\% fetal bovine serum (FBS) and maintained in a humidified atmosphere of 5\% CO2. The ES cell lines were E14TG2a (E14), obtained from the American Type Culture Collection (ATCC) and ZHBTc4 [25], donated by Dr. H. Niwa. They were cultured in ES culture medium, as described previously [17]. Goat anti-mouse PDGF-C-neutralizing antibody and control goat IgG were purchased from R\&D Systems. Synthesized RNAs were purchased from Operon Biotechnologies: 5'-GCCACAACGUCUAUAUCAUGG-3' and 5'-AUGAUAUAGACGUUGUGGCUG-3' were used to knockdown green fluorescent protein (GFP) [26], and 5'-UUGUACUCCG UUCUGUUCCUU-3' and 5'-GGAACAGAACGGAGUACAAG-3' were used to knockdown human PDGF-C. 
Plasmid construction and establishment of stable cell lines

For knockdown experiments, oligonucleotides containing target sequences for PDGF-C 5'-GCCAGGTTGTCTCCTGGTTAA-3' for hPDGFC(1304) and 5'-GTGGAG GAAATTGTGCCTGTT-3' for mPDGFC(1860) - were introduced into the artificial miRNA expression vector pcDNA6.2-GW/EmGFP miR (Invitrogen) to obtain pGW/ EmGFP-hPDGFC(1304) and pGW/EmGFP-mPDGFC(1860), respectively. Similarly, an oligonucleotide containing a target sequence for mPDGFC (5'-TGCATCCACTACA GTATTA-3') was inserted into pSilencer $\mathrm{H} 1$ puro (Thermo Fisher Scientific) to produce pSi-H1p-mPDGFC(469).

An inducible expression vector, pTRE-tTA2p-EmGFP-hPDGFC(1304), was constructed by transferring an EmGFP-hPDGFC miRNA(1304) cassette from pGW/EmGFPhPDGFC(1304) to pTRE-tTA2p [12]. To establish HT1080/hPDGFC(1304) cells, HT1080 cells were transfected with pTRE-tTA2p-EmGFP-hPDGFC(1304) using Lipofectamine 2000 (Invitrogen) and selected with $0.4 \mu \mathrm{g} / \mathrm{ml}$ puromycin in the presence of doxycycline.

Two plasmids, pCAGIP-EmGFP-control miRNA and pCAGIP-EmGFP-mPDGFC(1860), were constructed by transferring EmGFP-negative control miRNA and EmGFPmPDGFC(1860) cassettes from pcDNA6.2-GW/EmGFP-miR-neg control (Invitrogen) and pGW/EmGFP-mPDGFC(1860) into pCAG-IP [27], respectively. The construction of pCAG-dnSTAT3-IP, an expression vector for a dominant-negative STAT3, STAT3[Y705F], was described previously [10].

\section{RT-PCR}

Total RNA was extracted from individual cultured cells using Sepasol RNA I super G (Nacalai Tesque) or the RNeasy Plus Mini Kit (Qiagen), and cDNA synthesis was performed with ReverTra Ace (Toyobo) or using a high-capacity cDNA reverse transcription kit (Applied Biosystems). After PCR with the primers listed in Additional file 1: Table S1, amplified products were subjected to agarose gel electrophoresis.

\section{WST-1 assay and soft agar assay}

The proliferation of HT1080 cells was analyzed using WST-1 Cell Proliferation Reagent (Roche) according to the manufacturer's instructions. In brief, cells were seeded in 96-well microplates and cultured for 3 days. WST-1 reagent was then added to each well, and the number of viable cells was estimated by measuring absorbance at $450 \mathrm{~nm}$.

For the soft agar assay, the appropriate number of cells was seeded in $2.4 \mathrm{ml}$ of culture medium containing 0.4 or $0.5 \%$ Sea Plaque agarose (Lonza) and overlaid on $3 \mathrm{ml}$ of culture medium containing $0.53 \%$ Sea Plaque agarose in $6-\mathrm{cm}$ petri dishes. Cultures were maintained for approximately 2 weeks. Viable colonies were stained with 3-(4,5-dimethylthiazol-2-yl)-2,5-diphenyltetrazolium bromide (MTT; Nacalai Tesque), and stained colonies were counted by Image-J (NIH).

\section{Results}

\section{PDGF-C is highly expressed in HT1080 cells}

We examined the expression level of PDGF-C in the HT1080 fibrosarcoma cell line. When we compared mRNA expression levels of PDGF-C among 6 different tumor cell lines, PDGF-C was the most highly expressed in fibrosarcoma HT1080 cells (Fig. 1a). In addition, 


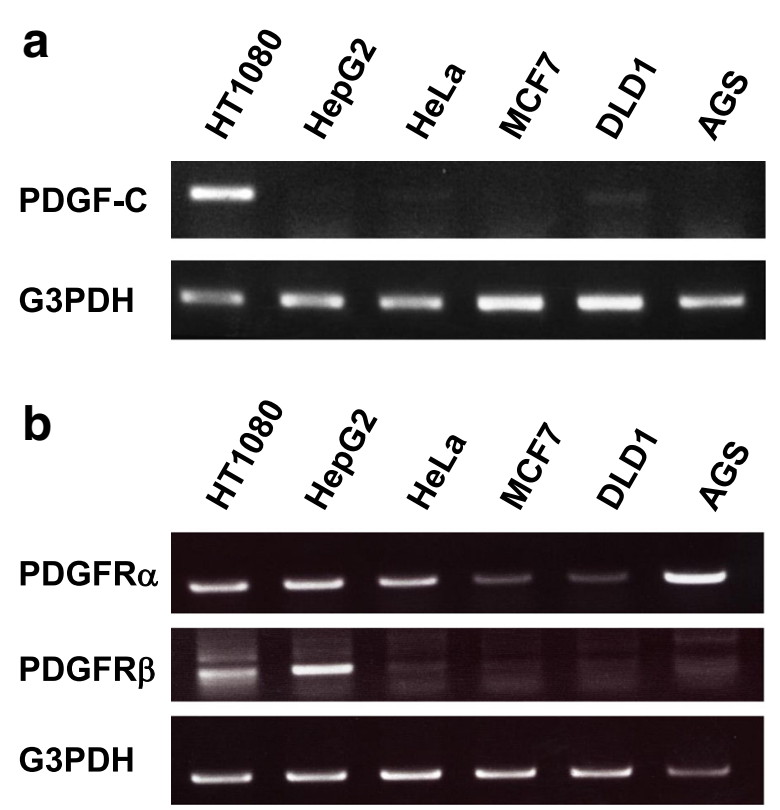

Fig. 1 The expression levels of PDGF-C (a) and PDGF receptor (b) for six different tumor cell lines: HT1080 (fibrosarcoma), HepG2 (hepatocellular carcinoma), HeLa (cervical carcinoma), MCF7 (breast carcinoma), DLD1 (colon carcinoma), and AGS (stomach carcinoma). In each case, total RNA was prepared and subjected to RT-PCR. Glycerol-3-phosphate dehydrogenase (G3PDH) was used as a loading control, and the results are representative of three independent experiments

as reported previously [28], we confirmed that HT1080 cells express both PDGF-R $\alpha$ and $\beta$ (Fig. 1b). Furthermore, the growth of HT1080 cells was significantly suppressed when exposed to $20 \mu \mathrm{M}$ of the chemical inhibitor AG1296, which inhibits the kinase activity of PDGF-R $\alpha$ and $\beta$ (Fig. 2a, Additional file 1: Figure S2a). These observations suggest that PDGF-C plays an important role in HT1080 cells.

PDGF-C is required for anchorage-dependent and -independent HT1080 cell growth We examined the requirement of PDGF-C for cell growth in HT1080 cells through knockdown experiments with artificial micro RNA (miRNA) against PDGF-C. We introduced an inducible expression plasmid carrying PDGF-C miRNA into HT1080 cells and established a transfectant, which we designated HT1080/hPDGFC(1304) (Additional file 1: Figure S1). In this transfectant cell line, the expression of PDGF-C can be maintained by the addition of doxycycline (Dox) to the culture medium. When we cultured HT1080/hPDGFC(1304) cells in the absence of Dox, PDGF-C expression was knocked down (Additional file 1: Figure S1c) and the growth of this transfectant was suppressed, although not significantly (Fig. 2b, Additional file 1: Figure S2b). When we performed another knockdown experiment using small interfering RNA (siRNA) against PDGF-C, PDGF-C knockdown significantly reduced the growth (Fig. 2c, Additional file 1: Figure S2c, S3). These results suggest that PDGF-C is required for the growth of HT1080 cells.

Unlike normal cells, transformed cells can grow in the absence of anchorage. We therefore examined whether PDGF-C is also required for anchorage-independent growth of HT1080 cells. PDGF-C knockdown induced by Dox removal suppressed the 

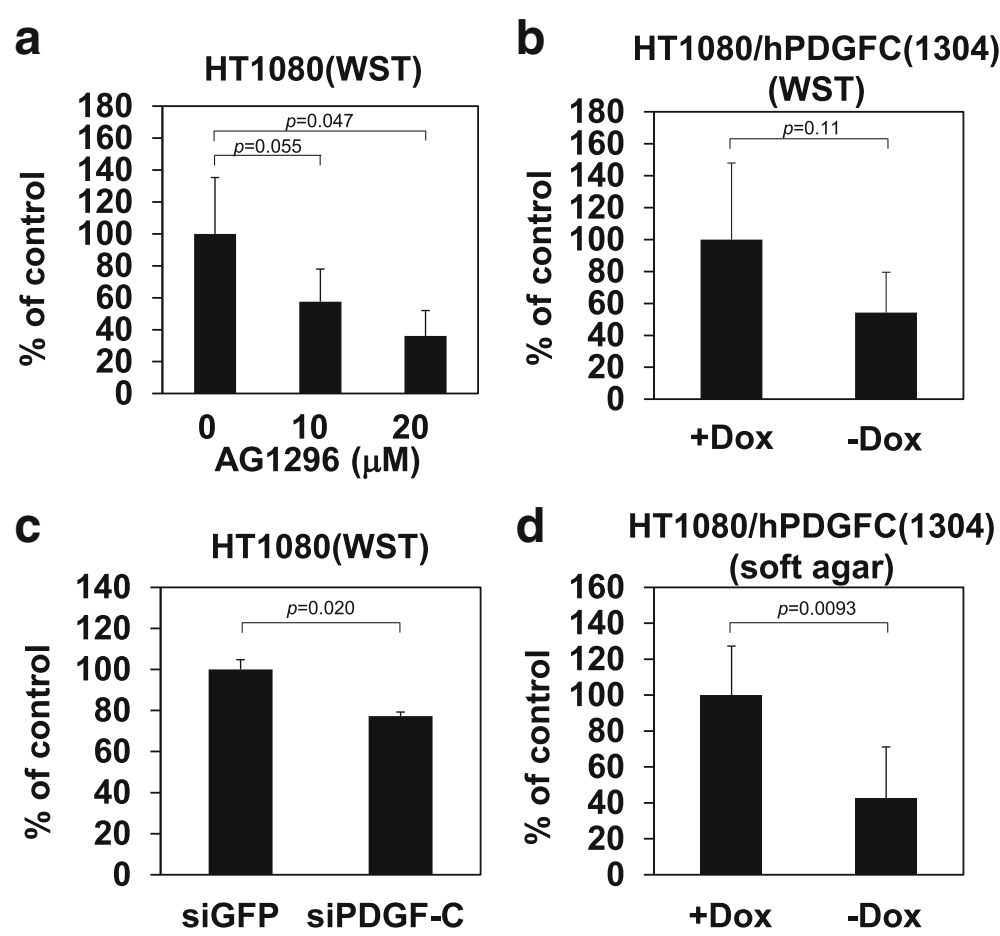

Fig. 2 The inhibition of PDGF-C results in HT1080 cell growth retardation. a The PDGF-R inhibitor suppresses the growth of HT1080 cells. HT1080 cells were cultured for 3 days with the indicated concentrations of AG1296 and subjected to the WST assay. $\mathbf{b}$ and $\mathbf{c}$ PDGF-C knockdown reduces the growth of HT1080 cells. b HT1080/ hPDGFC(1304) cells were treated with (+) or without (-) doxycycline (Dox) for 3 days and subjected to the WST assay. Notably, the expression of PDGF-C was repressed in the absence of doxycycline in HT1080/hPDGFC(1304) cells. c HT1080 cells were transfected with 500 nM of PDGF-C-specific siRNA (siPDGF-C) or negative control siRNA (siGFP), and subjected to the WST assay after a 3-day culture. d PDGF-C knockdown inhibits anchorageindependent growth of HT1080 cells. HT1080/hPDGFC(1304) cells were subjected to the soft agar assay with or without Dox for 2 weeks. In all the experiments, the average result for the control samples was set to $100 \%$, and the bars and error bars respectively represent the means and standard deviations $(n=3)$. Statistical analysis was performed using the two-tailed paired $t$ test. Statistical significance is defined as $p<0.05$. The raw data are shown in Additional file 1: Figure S2

anchorage-independent growth of HT1080/hPDGFC(1304) cells in soft agar (Fig. 2d, Additional file 1: Figure S2d). These results suggest that PDGF-C is involved in both anchorage-dependent and -independent growth of HT1080 cells.

PDGF-C is expressed in self-renewing ES cells and downregulated during ES cell differentiation

Our preliminary analysis suggested that PDGF-C is also expressed in self-renewing ES cells. We therefore examined the possible involvement of PDGF-C in ES cell growth. First, we confirmed that PDGF-C is expressed in self-renewing ES cells. E14 ES cells were cultured with or without LIF, and the expression levels of PDGF-C and the selfrenewal markers Oct $3 / 4$ and Rex 1 were examined. RT-PCR analyses revealed that PDGF-C is highly expressed in LIF-treated self-renewing ES cells and that its expression level decreases upon ES cell differentiation induced by LIF depletion (Fig. 3a).

Similar results were obtained when ES cell differentiation was induced through Oct3/4 depletion and STAT3 inhibition. In the Oct3/4 conditional knockout ES cell line ZHBTc4 


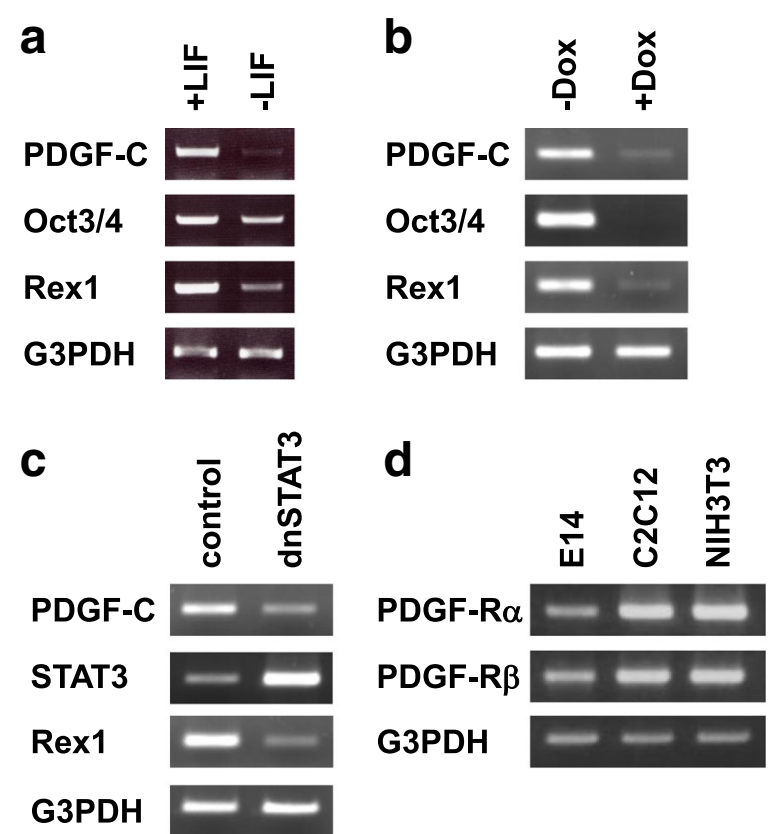

Fig. 3 PDGF-C is expressed in self-renewing ES cells and downregulated during ES cell differentiation. a Reduction of PDGF-C mRNA expression by LIF depletion. After culture with LIF for 3 days (+LIF) or without LIF for 6 days (-LIF), the expression levels of PDGF-C, Oct3/4 and Rex1 in the E14 ES cells were examined using RT-PCR. $\mathbf{b}$ The reduction in PDGF-C mRNA expression by Oct3/4 depletion. ZHBTc4 ES cells were cultured with (+) or without (-) doxycycline (Dox) for 2 days. Expression of the indicated genes was examined by RT-PCR. c Reduction of PDGF-C mRNA expression by the expression of a dominant-negative mutant of STAT3. After transfection with pCAG-IP (control) or pCAG-dnSTAT3-IP (dnSTAT3), E14 ES cells were cultured with puromycin for 2 days. Expression of the indicated genes was examined using RT-PCR. $\mathbf{d}$ Expression of PDGF receptors in ES cells. Total RNA was prepared from E14 ES cells, C2C12 myoblasts and NIH3T3 fibroblasts and subjected to RT-PCR. In all experiments, the results shown are representative of three independent experiments

[25], Dox-stimulated Oct3/4 repression led to a dramatic decrease in PDGF-C expression (Fig. 3b). Overexpression of a dominant-negative mutant of STAT3 in E14 ES cells also resulted in reduced expression levels of PDGF-C (Fig. 3c).

We also observed that both PDGF-R $\alpha$ and $\beta$ are expressed in E14 ES cells, although at lower levels than those in myoblasts and fibroblasts (Fig. 3d). Furthermore, the cell growth of ES cells showed a tendency to decrease when these receptors were inhibited by AG1296 (Fig. 4a, Additional file 1: Figure S4a). These results indicate that the expression of PDGF-C is restricted to undifferentiated ES cells and raise the possibility that PDGF-C functions as a growth factor in ES cells.

\section{PDGF-C is required for anchorage-dependent and -independent growth of ES cells}

We also examined the effect of PDGF-C knockdown on anchorage-dependent ES cell growth. When artificial miRNA and short-hairpin RNA (shRNA) against PDGF-C were expressed in E14 ES cells, their growth was reduced (Fig. 4b, Additional file 1: Figure S4b). Using RT-PCR, we confirmed that both miRNA and shRNA suppress the expression of endogenous PDGF-C mRNA (Additional file 1: Figure S5). Next, we inhibited PDGF-C activity using an anti-PDGF-C neutralizing antibody. Treatment with the neutralizing antibody led to the suppression of E14 ES cell growth (Fig. 4c, Additional file 1: Figure S4c). These results suggest that PDGF-C is involved in anchorage-dependent growth of ES cells. 


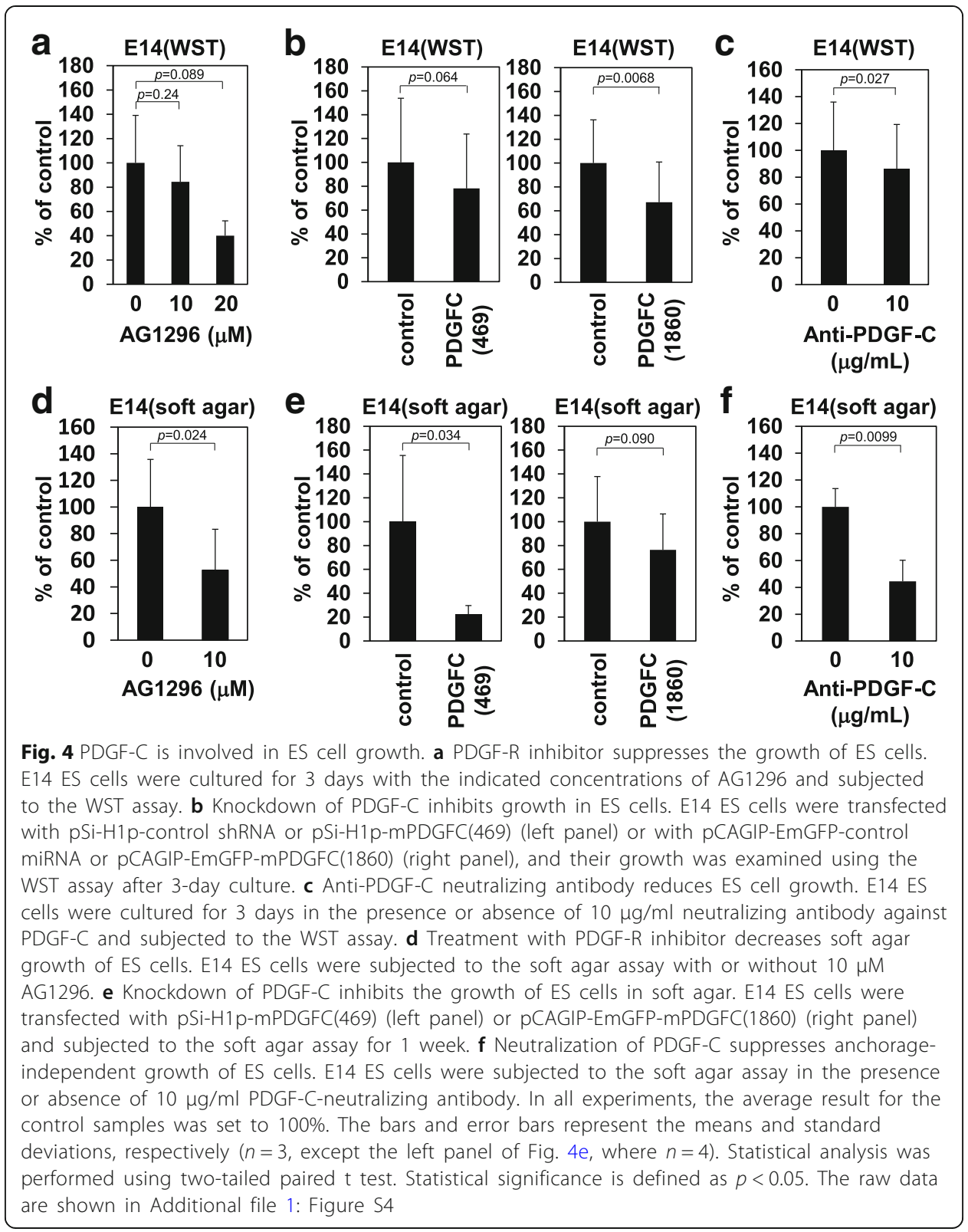

ES cells can grow under anchorage-independent conditions [17, 29], as expected since they can give rise to benign tumors called teratomas when injected into immunodeficient mice [30]. The PDGF-R inhibitor AG1296 suppressed anchorageindependent growth of E14 ES cells in soft agar (Fig. 4d, Additional file 1: Figure S4d). Thus, we explored the possibility that PDGF-C is also involved in anchorageindependent ES cell growth. PDGF-C knockdown suppressed the growth of E14 ES cells in soft agar (Fig. 4e, Additional file 1: Figure S4e). Similarly, the soft agar growth of E14 ES cells decreased when PDGF-C activity was inhibited by the presence of the PDGF-C neutralizing antibody (Fig. 4f, Additional file 1: Figure S4f). These results suggest that PDGF-C plays an essential role in anchorage-dependent and -independent ES cell growth. 


\section{Discussion}

PDGF-C autocrine signaling has been suggested for the growth of several tumor cells. Overexpression of this growth factor has been observed in brain tumors, colorectal tumors and rhabdomyosarcoma [31-33]. In colorectal tumors, PDGF-C overexpression is significantly associated with worse overall and relapse-free survival [31]. The enforced expression of PDGF-C has also been shown to promote the growth of breast cancer cells [34]. In this study, we demonstrated that PDGF-C promotes the growth of fibrosarcoma cells and ES cells.

In contrast to PDGF-A and -B, which are processed intracellularly, PDGF-C is secreted as a latent growth factor, and it requires proteolytic removal of its $\mathrm{N}$-terminal CUB domain for its activation [18-21]. Two serine proteases, plasmin and tissue plasminogen activator (tPA), can remove the CUB domain of PDGF-C $[19,22]$.

In primary mouse fibroblasts, tPA is endogenously expressed and activates PDGF-C expressed by the same cells, forming a tPA-mediated growth stimulatory loop [22]. Similarly, fibrosarcoma HT1080 cells have been shown to express both plasmin and tPA [35], suggesting that PDGF-C is activated by these two proteases in HT1080 cells. On the other hand, the expression and activity of tPA and urokinase-type plasminogen activator (uPA) are almost undetectable in ES cells [36]. Since plasmin is converted from plasminogen by either tPA or uPA, these observations suggest that ES cells lack both plasmin and tPA. Therefore, other proteases may be involved in PDGF-C activation in ES cells.

It is well-established that PDGF-C transmits its signal by binding to and activating PDGF-R. Our results using a PDGF-R inhibitor support this concept. Well-known downstream signaling pathways of this receptor are the PI3 kinase(PI3K)/Akt and the Ras/Erk pathways. Both play a critical role in cell growth and survival. In HT1080 fibrosarcoma cells, a decrease in Ras signaling due to the loss of an activated mutation in the N-ras gene reduced their anchorage-independent growth, and this reduction was restored through the ectopic expression of activated MEK [37]. By contrast, the overexpression of PTEN, an inhibitor of the PI3K/Akt pathway, has shown no effect on the cells' ability to form colonies in soft agar [28]. These results suggest that PDGF-C activates the Ras/Erk pathway, but not the PI3K/Akt pathway, to promote HT1080 cell growth.

In ES cells, the activation of the Ras/Erk pathway induces ES cell differentiation [27, 38], which leads to the suppression of cell growth, while the activation of Akt promotes ES cell self-renewal [39]. Therefore, in contrast to HT1080, the PI3K/Akt pathway may be a major downstream pathway of PDGF-C for the promotion of ES cell growth.

In this study, we used AG1296 as an inhibitor of PDGF receptors. This compound has been shown to inhibit c-kit, a close relative of the PDGF receptor [40]. HT1080 cells have been shown to highly express c-kit, probably through downregulation of miR-152 [41]. Knockout of c-kit in ES cells resulted in reduced growth rates, probably through the loss of spontaneously differentiating cells [42]. It is possible that c-kit or its ligand, stem cell factor, may also play a role in the growth of fibrosarcoma and ES cells.

PDGF-C promoted both anchorage-dependent and anchorage-independent growth of ES cells. This suggests that PDGF-C promotes the formation of teratoma when ES cells are transplanted. Because ES cells and induced pluripotent stem (iPS) cells have similar gene expression profiles, it is highly likely that PDGF-C is expressed in iPS cells. Considering the transforming potential of this growth factor, it is possible that high 
expression of PDGF-C in iPS cells increases the risk of tumor formation during cell therapy using iPS-derived cells.

LIF is a well-known factor that maintains self-renewal and promotes cell growth in mouse ES cells. Several other factors have been implicated in mouse ES cell growth and self-renewal, such as Wnt3a, which promotes the latter [5-7]. The hedgehog family seems to promote the former: Gli, a downstream molecule of hedgehog signaling, has been shown to be involved in ES cell growth [43, 44]. In addition, adrenocorticotropic hormone (ACTH) has been shown to promote the propagation of ES cells [45].

This study adds PDGF-C to the list of these growth factors for mouse ES cells. Considering that human ES cells are thought to be powerful materials for regenerative medicine, it would be interesting to examine whether PDGF-C can also promote the growth of human ES cells.

\section{Conclusions}

Our results show that PDGF-C is highly expressed in self-renewing mouse ES cells and in human fibrosarcoma cells. Suppression of PDGF-C results in growth retardation of both cell types. These findings indicate that PDGF-C plays an important role in the proliferation of fibrosarcoma and ES cells. Although further studies are needed, our results shed light on the potential application of PDGF-C in regenerative medicine that uses ES cells, as well as on the potential of this growth factor as a therapeutic target for fibrosarcoma.

\section{Additional file}

Additional file 1: Table S1. List of primers used for RT-PCR. Figure S1. Establishment of the HT1080 transfectant that expresses PDGF-C miRNA in a doxycycline-dependent manner. Figure S2. Inhibition of PDGF-C results in HT1080 cell growth retardation. Figure S3. Confirmation of PDGF-C knockdown by siRNA in HT1080 cells. Figure S4. PDGF-C is involved in ES cell growth. Figure S5. Confirmation of PDGF-C knockdown by shRNA (left panel) and miRNA (right panel) in E14 ES cells. (PDF $5629 \mathrm{~kb}$ )

\section{Abbreviations}

Dox: Doxycycline; ES: Embryonic stem; iPS: induced pluripotent stem; LIF: Leukemia inhibitory factor; miRNA: micro RNA; PDGF: Platelet-derived growth factor; PDGF-R: PDGF receptor; PI3K: PI3 kinase; shRNA: short-hairpin RNA; siRNA: small interfering RNA; tPA: tissue plasminogen activator

\section{Acknowledgments}

We are grateful to Dr. Hitoshi Niwa (Institute of Molecular Embryology and Genetics, Kumamoto University) for the kind donation of ZHBTc4 cells, and to the Center for Biomedical Research and Education at Kanazawa University for the use of their DNA sequencer. We would also to thank Enago (www.enago.jp) for the English language review.

\section{Funding}

This work was partly supported by a Grant-in-Aid for Scientific Research (KAKENHI 22370050 and 16 K07126) from the Japan Society for the Promotion of Science (JSPS) and a grant from Juntendo University Research Institute for Diseases of Old Age.

Availability of data and materials

The data sets generated and/or analyzed during this study are available from the corresponding author on reasonable request.

\section{Authors' contributions}

TK, CS, TI, TI and HK performed the experiments and analyzed the data. TK, YT, TA, TY and HK developed the concept of the project. TK and HK were involved in writing the paper. All authors read and approved the final manuscript.

Ethics approval and consent to participate

Not applicable 


\section{Competing interests}

The authors declare that they have no competing interests.

\section{Publisher's Note}

Springer Nature remains neutral with regard to jurisdictional claims in published maps and institutional affiliations.

\section{Author details}

${ }^{1}$ Department of Stem Cell Biology, Graduate School of Medical Sciences, Kanazawa University, Kanazawa, Ishikawa, Japan. 'Laboratory of Molecular and Biochemical Research, Research Support Center, Juntendo University Graduate School of Medicine, 2-1-1 Hongo, Bunkyo-ku, Tokyo 113-8421, Japan. ${ }^{3}$ Present address: Department of Diagnostic Imaging and Nuclear Medicine, Graduate School of Medicine, Kyoto University, Sakyo-ku, Kyoto, Japan. ${ }^{4}$ Present address: Neusoft Xikang Healthcare Technology Co., Ltd., Shenyang, China. ${ }^{5}$ Present address: RIKEN BioResource Center, Tsukuba, Ibaraki, Japan.

\section{Received: 25 October 2017 Accepted: 20 February 2018}

Published online: 27 February 2018

\section{References}

1. Niwa H. How is pluripotency determined and maintained? Development. 2007;134:635-46.

2. Koide H. Embryonic stem cells and oncogenes. In: Atwood CS, Meethal SV, editors. Pluripotent stem cell biology advances in mechanisms, methods and models. Rijeka: InTech; 2014. p. 41-61.

3. Niwa H, Burdon T, Chambers I, Smith A. Self-renewal of pluripotent embryonic stem cells is mediated via activation of STAT3. Genes Dev. 1998;12:2048-60.

4. Matsuda T, Nakamura T, Nakao K, Arai T, Katsuki M, Heike T, Yokota T. STAT3 activation is sufficient to maintain an undifferentiated state of mouse embryonic stem cells. EMBO J. 1999;18:4261-9.

5. Hao J, Li TG, Qi X, Zhao DF, Zhao GQ. WNT/beta-catenin pathway up-regulates Stat3 and converges on LIF to prevent differentiation of mouse embryonic stem cells. Dev Biol. 2006;290:81-91.

6. Ogawa K, Nishinakamura R, Iwamatsu Y, Shimosato D, Niwa H. Synergistic action of Wnt and LIF in maintaining pluripotency of mouse ES cells. Biochem Biophys Res Commun. 2006:343:159-66.

7. Singla DK, Schneider DJ, LeWinter MM, Sobel BE. Wnt3a but not wnt11 supports self-renewal of embryonic stem cells. Biochem Biophys Res Commun. 2006;345:789-95.

8. Takao Y, Yokota T, Koide H. $\beta$-catenin up-regulates Nanog expression through interaction with Oct-3/4 in embryonic stem cells. Biochem Biophys Res Commun. 2007;353:699-705.

9. Ben-Porath I, Thomson MW, Carey VJ, Ge R, Bell GW, Regev A, Weinberg RA. An embryonic stem cell-like gene expression signature in poorly differentiated aggressive human tumors. Nat Genet. 2008;40:499-507.

10. Akagi T, Usuda M, Matsuda T, Ko MSH, Niwa H, Asano M, Koide H, Yokota T. Identification of Zfp-57 as a downstream molecule of STAT3 and Oct-3/4 in embryonic stem cells. Biochem Biophys Res Commun. 2005;331:23-30

11. Kinoshita K, Ura H, Akagi T, Usuda M, Koide H, Yokota T. GABPa regulates Oct-3/4 expression in mouse embryonic stem cells. Biochem Biophys Res Commun. 2007;353:686-91.

12. Ura H, Usuda M, Kinoshita K, Sun C, Mori K, Akagi T, Matsuda T, Koide H, Yokota T. STAT3 and Oct-3/4 control histone modification through induction of Eed in embryonic stem cells. J Biol Chem. 2008;283:9713-23.

13. Sun C, Nakatake Y, Ura H, Akagi T, Niwa H, Koide H, Yokota T. Stem cell-specific expression of Dax1 is conferred by STAT3 and Oct3/4 in embryonic stem cells. Biochem Biophys Res Commun. 2008;372:91-6.

14. Miura M, Ueda A, Takao Y, Nishimura EK, Koide H, Yokota T. A stem cell-derived gene (Sddr) negatively regulates differentiation of embryonic stem cells. Int J Dev Biol. 2010;54:33-9.

15. Fujii Y, Kakegawa M, Koide H, Akagi T, Yokota T. Zfp296 is a novel Klf4-interacting protein and functions as a negative regulator. Biochem Biophys Res Commun. 2013;441:411-7.

16. Kanai $\mathrm{D}$, Ueda A, Akagi T, Yokota T, Koide H. Oct3/4 directly regulates expression of E2F3a in mouse embryonic stem cells. Biochem Biophys Res Commun. 2015;459:374-8.

17. Tada $Y$, Yamaguchi $Y$, Kinjo $T$, Song $X$, Akagi $T$, Takamura $H$, Ohta $T$, Yokota $T$, Koide $H$. The stem cell transcription factor ZFP57 induces IGF2 expression to promote anchorage-independent growth in cancer cells. Oncogene. 2015;34:752-60.

18. Lei H, Kazlauskas A. Focus on molecules: platelet-derived growth factor C, PDGF-C. Exp Eye Res. 2008:86:711-2

19. Li X, Pontén A, Aase K, Karlsson L, Abramsson A, Uutela M, Bäckström G, Hellström M, Boström H, Li H, Soriano P, Betsholtz C, Heldin C-H, Alitalo K, Östman A, Eriksson U. PDGF-C is a new protease-activated ligand for the PDGF a-receptor. Nat Cell Biol. 2000;2:302-9.

20. Li X, Eriksson U. Novel PDGF family members: PDGF-C and PDGF-D. Cytokine Growth Factor Rev. 2003:14:91-8.

21. Andrae J, Gallini R, Betsholtz C. Role of platelet-derived growth factors in physiology and medicine. Genes Dev. 2008:22:1276-312.

22. Fredriksson L, Li H, Fieber C, Li X, Eriksson U. Tissue plasminogen activator is a potent activator of PDGF-CC. EMBO J. 2004;23:3793-802.

23. Zwerner JP, May WA. PDGF-C is an EWS/FLI induced transforming growth factor in Ewing family tumors. Oncogene. 2001;20:626-33.

24. Zwerner JP, May WA. Dominant negative PDGF-C inhibits growth of Ewing family tumor cell lines. Oncogene. 2002;21:3847-54

25. Niwa H, Miyazaki J, Smith AG. Quantitative expression of Oct-3/4 defines differentiation, dedifferentiation or selfrenewal of ES cells. Nat Genet. 2000;24:372-6.

26. Uranishi K, Akagi T, Sun C, Koide H, Yokota T. Dax1 associates with Esrrb and regulates its function in embryonic stem cells. Mol Cell Biol. 2013;33:2056-66. 
27. Yoshida-Koide U, Matsuda T, Saikawa K, Nakanuma Y, Yokota T, Asashima M, Koide H. Involvement of Ras in extraembryonic endoderm differentiation of embryonic stem cells. Biochem Biophys Res Commun. 2004;313:475-81.

28. Gupta S, Stuffrein S, Plattner R, Tencati M, Gray C, Whang YE, Stanbridge EJ. Role of phosphoinositide 3-kinase in the aggressive tumor growth of HT1080 human fibrosarcoma cells. Mol Cell Biol. 2001;21:5846-56.

29. Yamaguchi Y, Takamura H, Tada Y, Akagi T, Oyama K, Miyashita T, Tajima H, Kitagawa H, Fushida S, Yokota T, Ohta T, Koide H. Nanog positively regulates Zfp57 expression in mouse embryonic stem cells. Biochem Biophys Res Commun. 2014:453:817-20.

30. Smith AG. Embryo-derived stem cells: of mice and men. Annu Rev Cell Dev Biol. 2001;17:435-62.

31. Yamauchi S, lida S, Ishiguro M, Ishikawa T, Uetake H, Sugihara K. Clinical significance of platelet-derived growth factor-C expression in colorectal cancer. J Cancer Therapy. 2014;5:11-20.

32. Lokker NA, Sullivan CM, Hollenbach SJ, Israel MA, Giese NA. Platelet-derived growth factor (PDGF) autocrine signaling regulates survival and mitogenic pathways in glioblastoma cells: evidence that the novel PDGF-C and PDGF-D ligands may play a role in the development of brain tumors. Cancer Res. 2002:62:3729-35.

33. Ehnman M, Missiaglia E, Folestad E, Selfe J, Strell C, Thway K, Brodin B, Pietras K, Shipley J, Östman A, Eriksson U. Distinct effects of ligand-induced PDGFRa and PDGFRß signaling in the human rhabdomyosarcoma tumor cell and stroma cell compartments. Cancer Res. 2013;73:2139-49.

34. Hurst NJ Jr, Najy AJ, Ustach CV, Movilla L, Kim H-RC. Platelet-derived growth factor-C (PDGF-C) activation by serine proteases: implications for breast cancer progression. Biochem J. 2012;441:909-18.

35. Choi KS, Fogg DK, Yoon CS, Waisman DM. p11 regulates extracellular plasmin production and invasiveness of HT1080 fibrosarcoma cells. FASEB J. 2003;17:235-46.

36. Hadadeh O, Barruet E, Peiretti F, Verdier M, Bernot D, Hadjal Y, Yazidi CE, Robaglia-Schlupp A, De Paula AM, Nègre D, lacovino M, Kyba M, Alessi MC, Binétruy B. The plasminogen activation system modulates differently adipogenesis and myogenesis of embryonic stem cells. PLoS One. 2012;7:e49065.

37. Gupta S, Plattner R, Der CJ, Stanbridge EJ. Dissection of ras-dependent signaling pathways controlling aggressive tumor growth of human fibrosarcoma cells: evidence for a potential novel pathway. Mol Cell Biol. 2000;20:9294-306.

38. Burdon T, Stracey C, Chambers I, Nichols J, Smith A. Suppression of SHP-2 and ERK signalling promotes selfrenewal of mouse embryonic stem cells. Dev Biol. 1999;210:30-43.

39. Watanabe S, Umehara H, Murayama K, Okabe M, Kimura T, Nakano T. Activation of Akt signaling is sufficient to maintain pluripotency in mouse and primate embryonic stem cells. Oncogene. 2006;25:2697-707.

40. Kovalenko M, Gazit A, Böhmer A, Rorsman C, Rönnstrand L, Heldin CH, Waltenberger J, Böhmer FD, Levitzk A. Selective platelet-derived growth factor receptor kinase blockers reverse sis-transformation. Cancer Res. 1994:54:6106-14

41. Pazzaglia L, Novello C, Conti A, Pollino S, Picci P, Benassi MS. miR-152 down-regulation is associated with MET up-regulation in leiomyosarcoma and undifferentiated pleomorphic sarcoma. Cell Oncol. 2017:40:77-88.

42. Bashamboo A, Taylor AH, Samuel K, Panthier JJ, Whetton AD, Forrester LM. The survival of differentiating embryonic stem cells is dependent on the SCF-KIT pathway. J Cell Sci. 2006:119:3039-46.

43. Heo JS, Lee MY, Han HJ. Sonic hedgehog stimulates mouse embryonic stem cell proliferation by cooperation of $\mathrm{Ca}^{2}$ +/protein kinase C and epidermal growth factor receptor as well as Gli1 activation. Stem Cells. 2007:25:3069-80

44. Ueda A. Involvement of Gli proteins in undifferentiated state maintenance and proliferation of embryonic stem cells. J Juzen Med Soc. 2012;121:38-46.

45. Ogawa K, Matsui H, Ohtsuka S, Niwa H. A novel mechanism for regulating clonal propagation of mouse ES cells. Genes Cells. 2004;9:471-7.

\section{Submit your next manuscript to BioMed Central and we will help you at every step:}

- We accept pre-submission inquiries

- Our selector tool helps you to find the most relevant journal

- We provide round the clock customer support

- Convenient online submission

- Thorough peer review

- Inclusion in PubMed and all major indexing services

- Maximum visibility for your research

Submit your manuscript at www biomedcentral com/submit

O Biomed Central 